\title{
The Effect of Caffeine on Health and Exercise Performance with a Cold Brew Coffee Approach: A Scoping Review
}

\author{
Hoseyn Fatolahi*1 ${ }^{1}$, Alireza Farahmand ${ }^{2}$, Shabnam Rezakhani ${ }^{3}$ \\ 1- Department of Physical Education, Pardis Branch, Islamic Azad University, Pardis, Iran \\ 2- Department of Physical Education, Central Tehran Branch, Islamic Azad University, Tehran, Iran \\ 3- Faculty of Nutrition and Food Technology, National Nutrition and Food Technology Research Institute, Shahid Beheshti University of Medical \\ Sciences, Tehran, Iran
}

\begin{abstract}
A B S T R A C T
Based on the effects of coffee and caffeine, in particular, a review study is needed to investigate associations between the caffeine consumption and its health-linked effects. Furthermore, effects of coffee on sport performance have not fully been elucidated. Based on the increased popularity of the cold-brew coffee, this study has provided a comprehensive overview of the effects of cold-brew coffee on health and exercise performance. Databases (PubMed, Science Direct and Google Scholar) were searched for articles on human models. Totally, 2805 articles were identified from 2000 to 2020. Keywords included coffee, caffeine, cold brew, exercise, training and sports performance. Studies involving caffeinesuppressing drugs and animal studies and cases with physical limitations were excluded and thus 84 articles were identified. Results showed that consumption of 3 to 4 cups of coffee (300-400 mg/day) was associated with decreased risk factors of cancers, cardiovascular diseases, diabetes and Alzheimer disease. It is noteworthy that caffeine intake in specific groups, particularly in women, needs special consideration. However, health benefits of the cold-brew coffee seem to be greater due to the drink low acidity and high antioxidant activity. In this study, the most important factor included decreases in chlorogenic acid. Moreover, consumption of cold-brew coffee in warm weather prevented hyperthermia. In fact, $3-9 \mathrm{mg} / \mathrm{kg}$ of caffeine improved physical performance in resistance and endurance exercises. Caffeine consumption could increase lipid oxidation in aerobic exercises as well as stimulate sympathetic nerves in anaerobic exercises. However, investigation of the acute and chronic effects of consuming coffee in various contexts to achieve integrated results needs further investigations.
\end{abstract}

Keywords: Coffee, Caffeine, Health, Cold brew, Sports performance

\section{Introduction}

Coffee is the main source of caffeine and is widely consumed around the world. (1). By population, Brazilians rank the largest coffee consumers in world, with 1.32 cups of coffee daily (2). Consumption of coffee in Iran is nearly 1,000 tons/year, with each Iranian drinks $2-3 \mathrm{~g} /$ day (0.028 cups/day) of coffee on average $(3,4)$. By increasing interests in roles of coffee in public health, investigation of patterns of population consumption seems further important. Various studies have been carried out on effects of coffee on health (5). Roasted coffee contains numerous bioactive compounds with antiinflammatory and anti-cancer properties (6). Researchers have reported that coffee consumption decreases mortality $(17 \%)$, cardiovascular diseases (17\%) (7) and risk of cancers (18\%) (8). With the exception of pregnancy, where high consumption of coffee is associated with low birth weight, preterm birth and decreased chance of pregnancy, consumption of three to four (or more) cups of coffee daily decreases risk of several specific cancers and improves neurological, metabolic and liver cell functions (9). Results of the studies have revealed that despite inverse non-linear relationships between the coffee consumption and the hypertension, normal coffee consumption is not directly linked to hypertension $(10,11)$. In addition, consumption of energy drinks, including coffee, in athletes and nonathletes is used as a supplement to improve performance (12). Recent studies have shown that coffee consumption includes verified effects on signal pathways of the sport performance $(13,14)$ and that caffeine is known as an ergogenic aid (15). However, debates on coffee consumption volume and its effects 
on various exercise performances are still in progress $(16,17)$. Therefore, this review was carried out to better understand how to consume coffee or caffeine and how to prepare them to increase athletic performance and health. Studies have suggested various specific prescriptions based on the participant athletic or physical condition and the study method. For example, caffeine intake has been studied with other energy-producing factors; however, it has been reported that caffeine is the most important energyenhancing factor (18).

It has been shown that quantitative and qualitative characteristics of the coffee are affected by several factors, including coffee variety, roasting method, processing method, temperature, packaging and preparation $(19,20)$. Due to the aroma, taste, complex characteristics and diverse needs of coffee consumers, various studies have been carried out on analysis of the processing devices (21) as well as coffee functional properties (22) and sensory aspects (23). Consumption of cold-brew coffees (or ready-todrink, RTD) have become popular, especially in markets (24). A $460 \%$ increase in consumption of cold-brew coffee in the United States between 2015 and 2017 has been reported (25) Invests in rapidly growing markets such as cold-brew coffees have been reported for several reasons, including colder slower brewing processes alter favor, aroma and bioactive compounds (3). However, health-linked benefits of the cold-brew coffee consumption are still controversial. Hot coffee consumption may include further exothermic effects in hot seasons and it is important to find an appropriate alternative for people, who are addicted to coffee. A systematic review on the relevant published articles can result in classification of the scientific recommendations in health and exercise physiology. It is noteworthy that studies on caffeine-based sports drinks have focused on competition times or exercise and only limited studies have assessed these effects on daily coffee consumption. Therefore, the aim of this study was to summarize current knowledge of caffeine effects on human health and exercise performance using coldbrew coffee approach. Results from this review study hopefully provide directions for future studies and help athletes better use ergogenic effects of caffeine.

\section{Methodology}

In the present review study, three electronic databases of PubMed, Science Direct and Google Scholar were searched to find eligible studies published from January 2000 to January 2020. Keywords included coffee, caffeine, cold brew, exercise, training and sports performance, covering articles of human models. Totally, 2805 articles were identified. Inclusion criteria included empirical studies assessing effects of caffeine consumption as an independent variable and its effects on health and sport performance. Furthermore, meta-analyses were used to provide general findings. Studies involving caffeine-suppressing drugs, animal studies and cases with physical limitations or specific dietary plans were excluded. After a careful review and elimination of duplicates using Endnote Software v.9 (Microsoft, USA), 84 quality articles were identified and used in the present study. From each eligible study, abstracts, results, study designs, coffee types, studies numbers, statistical samples, consumed coffee volumes, dose responses or cup number and effect sizes were extracted (Figure 1).

\section{Methods of making coffee drinks}

Coffee preparation is the process of converting coffee beans into drinks, while specific stages of each method vary depending on the type of coffee and raw materials. The process involves four basic steps of roasting, milling, mixing with water (brewing) and separating coffee. All methods of coffee brewing can be divided into four major categories of boiling, pressing, filtering and wetting with differences in adding water (20). Most coffees used in different countries are prepared using different methods of boiling (26). Studies have shown that roasting temperature and size of the mill affect concentration of the soluble compounds. Increased temperature is associated with decreased chlorogenic acid and processable caffeine concentrations (27). 

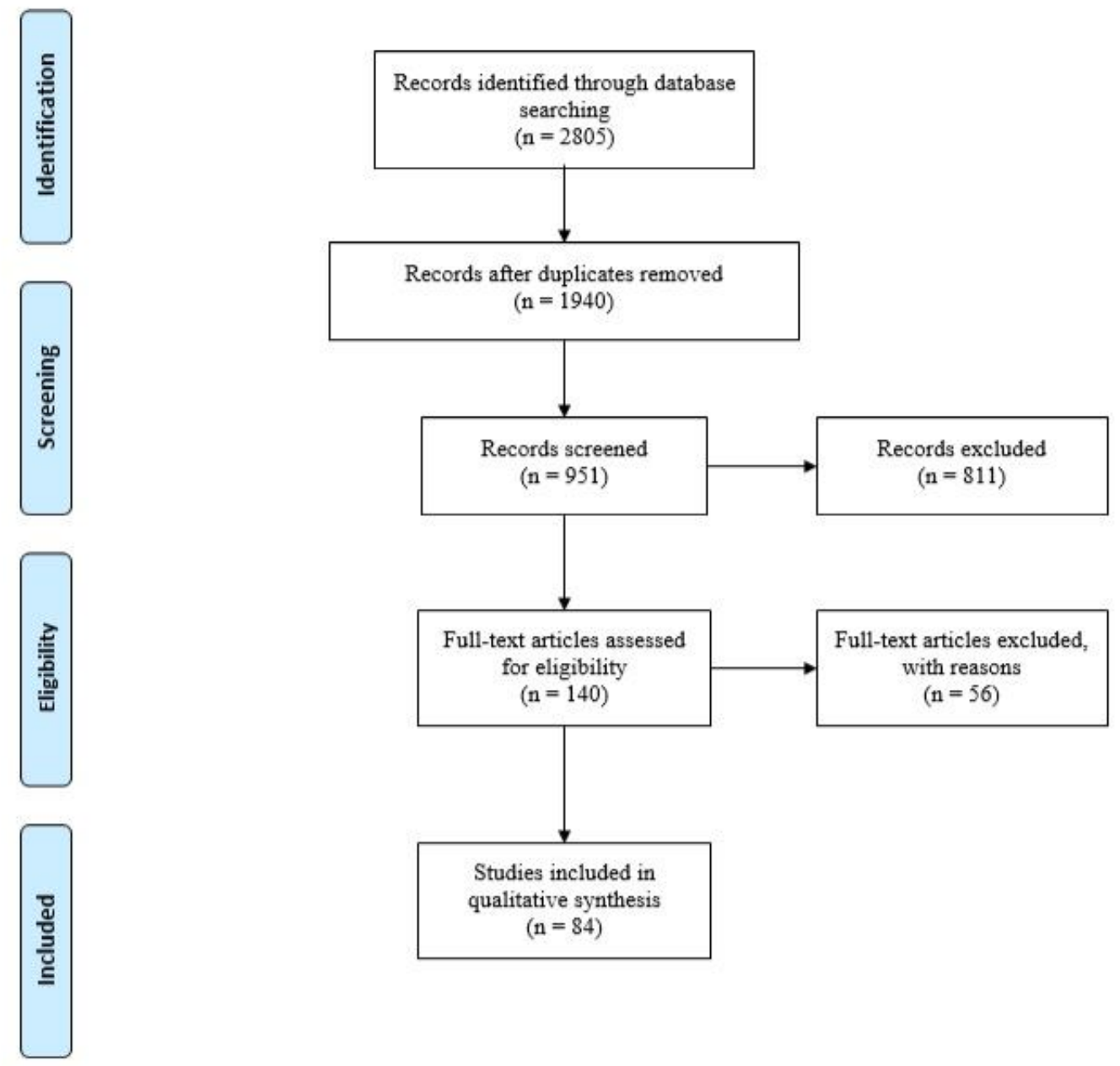

Figure 1. Results of database searching on the base of PRISMA Group

Chlorogenic acid compounds, as active antioxidants, transfer bitterness to coffee and cause health-linked benefits. These bioactive compounds have been used in numerous studies on extended health or risk effects of the coffee beverages (28-30). Researchers have found that caffeine is responsible for the symptoms of gastric irritation following decreases in gastric reflex after consumption of decaffeinated coffees (31). However, recent studies detected no significant relationships between the coffee consumption and four major gastrointestinal disorders of gastric ulcer, duodenal ulcer and esophageal reflux $(8,32)$. According to Bloomberg report, " "cold brew might save the coffee market". Coffee-shop sales of hot coffee fell $3 \%$ in 2016, while

\footnotetext{
1 - Marvin G Perez. (2017). Cold Brew Might Save the Coffee Market. https://www.bloomberg.com/news/articles/2017-07-19
}

cold-brewed coffee sales grew up nearly $80 \%$, compared to its last year record. Based on the reported controversies on health-linked effects of hot coffee, it is necessary to assess acidity, caffeine and antioxidant activity of other cauliflower coffees (30). Recent studies have highlighted therapeutic roles of the chlorogenic acids on health of the human brain (25). Understanding of the antioxidant effects of various coffee brewing methods is still uncompleted (33).

One of the various coffees based on the filtering methods is cold-brew or cold-press coffee. In this method, the coffee is prepared by long contact (8-24 h) with cold water using special condensation filter and then is added with warm water at 3:1 ratio. Coffee prepared with this method includes a low acidity and a sweeter taste and is often preferred by people with sensitive stomach (20). The cold-brew 
coffee has recently been released by the coffee industries, especially in warm weathers (34). However, a little research has been carried out on these coffee chemical properties, including $\mathrm{pH}$ and antioxidant activity as well as health-associated effects. In a late study, all samples of the cold-brew coffees were found to include low concentrations of acidic compounds, compared to that the samples of boiled coffee did. Cold-brew coffee includes several low molecular weight compounds, including carboxylic acids such as citric, malic, quinic, succinic and gluconic acids. However, a strong correlation is found in cold-brew coffee between the total caffeoylquinic acid (CQA) concentration and antioxidant activity (30). Results have shown that concentrations of chlorogenic acid and caffeine are higher in medium roasted coffee than high roasted coffee. Size of the milled coffee did not significantly affect concentrations of chlorogenic acid and caffeine in samples of cold-brew coffees. Concentrations of caffeine in coarse-grained samples of the cold-brew coffee were significantly higher than those other hot coffees. It also seems that concentrations of caffeine and chlorogenic acid in all samples of the cold-brew coffee are balanced within 6-7 h and need no further time (29). According to Angeloni et al. (2019), sensory properties of coffee vary with the processing methods and these sensory properties are affected by the process or temperature (24). In terms of the structural aspects, caffeine and volatile compounds of coffee include no significant relationships with human general tendencies, whereas chlorogenic acid and trigonellin are inversely linked to human sensory intentions (35). These results provide information on cold brew sensory profiles and can be used for coffee productions or marketing strategies. However, at the time of publication, a very little information was available on the chemistry of cold-brew coffee and very low published studies on the health-related effects of cold-brew coffee.

\section{Biochemical, nutritional and health}

\section{properties of the cold-brew coffee}

Caffeine contains methylxanthines, the alkaloids with similar properties to theophylline and theobromine (36). As previously stated, roasted coffee contains several bioactive compounds such as caffeine, chlorogenic acid, diterpenes, cafestol, kahweol and trigonelline (6). Advances in detailed analysis of the human genome, transcriptome, proteome and metabolome have provided researchers opportunities to achieve further detailed information on the health-linked effects of caffeine. Thus, several genetic variations have been identified associated with daily consumptions of coffee and caffeine (37). Barnung et al. (2018) linked effects of coffee consumption to metabolic, immune and inflammatory signaling pathways based on the results of gene expression analyses (38). Based on the study of biological systems of the body, positive relationships have been reported between daily caffeine intake and improvement of myocardial blood flow (39) as well as decreased symptoms of liver fibrosis (40), depression (41), hearing (42), cognitive parameters (43) and ileus obstruction (44). Researchers have detected that high caffeine intake (> $1000 \mathrm{mg} / \mathrm{w}$ ) is a risk factor associated with anxiety and depression. However, these effects were sometimes detected at lower doses. The positive effects of caffeine intake are generally seen in consumers with low well-being, mental health problems such as depression and anxiety and self-medications such as energy drinks in short-terms (45). These positive effects are seen only in coffees with caffeine and caffeine-free coffees lack these properties (4). Quitting daily caffeine intake can cause headache, lack of energy and drowsiness (46). Researchers recommend that infants and children refrain consumption of caffeinated drinks to avoid anxiety or nervousness (47). Caffeine can also include major effects on sleep habits. High caffeine intake is associated with decreased eye movement speed in the REM sleep phase. Effects of caffeine on reproductive system need further investigations (48).

Coffee preparation techniques seem to involve antioxidant compounds associated with coffee flavor, taste, digestibility and health $(20,22,23)$. Quantities of caffeine in cold-brew coffees increase calorie intakes at rest and thus decrease or maintain body weight. The $13 \%$ increase in basal metabolism caused by the consumption of cold-brew coffee doubles the circulation of lipids, with $24 \%$ being oxidized and $76 \%$ recycled, although no integrated reviews are available (49). Studies have shown that caffeine intake changes mood, especially in sleep-deprived people. Cold-brew coffees can improve mood and brain function while decreasing risk of depression (50). By every cup of coffee consumed per day, risk of depression is decreased by nearly $8 \%$. 
Furthermore, coffee boosts mood and brain function in elderly people by $17 \%$ (51). Phenolic compounds, magnesium, trigonline and quinoids decrease risk of heart diseases by up to $15 \%$. These elements increase insulin sensitivity, stabilize blood sugar and lower blood pressure (52). Moreover, caffeine acts as an antioxidant and anti-inflammatory agent with chlorogenic acid and diterpenes (53). Evidence suggest that people with uncontrolled hypertension should refrain from regular caffeine intake daily. However, effects of consumption of more than 600 mg (six cups) of caffeine per day have not been studied in healthy people (54). A review of studies shows that coffee consumption includes significant inverse relationships with type II diabetes. In middleaged people, regular drinking of 4-6 cups of coldbrew coffee per day may decrease risk of type 2 diabetes by up to $30 \%$ due to the presence of chlorogenic acid $(55,56)$.

Consumption of coffee regulates intestinal peptides that slow digestion process and keep blood sugar constant (57). However, results of a study in Finland with 14 years of case follow-up showed that drinking six cups of boiled coffee daily was not associated with type II diabetes (55). In addition to increasing mental concentration and mood, drinking cold-brew coffee protects brain function from age-linked diseases (58). An observational study showed that people who daily consumed 3-5 cups of coffee during their middle age were $65 \%$ less likely to have dementia and Alzheimer's disease at older ages (59). Another study stated that coffee drinkers were five times less likely to develop Parkinson's disease (60). Several compounds in caffeinated coffee (phenolic, norharman and Harman) protect against Alzheimer's and Parkinson's diseases (61), while decaffeinated coffee does not seem to include similar protective benefits (62). Many people avoid coffees because of stimulating acid reflux and causing stomach upset and irritation. Generally, acidity of hot coffee and cobalt coffee are in ranges of 5-6; however, studies have shown that cobalt coffee is less acidic (29, 30). Another reason that the latter drink may be less irritating is linked to its crude polysaccharide contents. These carbohydrates, or chains of sugar molecules, enhance digestive immunity. Cold-brew coffees also contain compounds that protect the stomach from acidity (63). A longitudinal study of men and women aging 50 to 71 years demonstrated that over-consumption of this coffee decreased risk of heart diseases, respiratory diseases, strokes, injuries, diabetes and infections (64). A possible reason for this association includes the presence of potent antioxidants such as polyphenols, hydroxycinnamates and chlorogenic acid (65). Although studies have shown that hot coffees contain more antioxidants than that cold-brew coffees do, strong antioxidants such as caffeoylquinic acid (CQA) in cold-brew coffees are not found in hot coffees (66).

\section{Caffeine as an ergogenic aid in exercise performance}

High caffeine use by athletes has urged researchers to focus on the optimal guidelines for caffeine effects on exercise and exercise performance (67). Caffeine is widely used during competitions and exercises because of its ergogenic properties, including central nervous system (CNS) stimulation and muscle strengthening $(68,69)$. Caffeine improves numerous cognitive and behavioral mechanisms, including sport performances, anaerobic and aerobic powers, cognitive functions, alertness, energy levels and fatigues (70). Ergogenic effects of caffeine are commonly seen at doses of 3-9 mg/kg (71). However, quality of exercise, fitness or athletic recovery may be diminished by the side effects of caffeine such as anxiety and sleep disorders (72). Caffeine intake can increase blood pressure, heart rate and catecholamine production and increase risk of the heart attack, especially during racing (73). Effects of caffeine are likely to be moderated by various interpersonal factors, including gender, age, drug use, circadian factors, time and volume of consumption, caffeine tolerance threshold, body mass, health status and genetic background $(74,75)$. These affect ergogenic responses of caffeine to a wide range of exercise tasks and cognitive skills such as endurance performances (lipid oxidation), weight liftings, reaction times, motivations, beliefs and habits of caffeine intake (76). Researchers from various sports have found that moderate doses of caffeine include a small but significant effect on endurance performance. These also improve overall average power output and timing of the trailer race by $30 \mathrm{~min}$, compared to placebos $(14,77)$ 
Table 1. Result of the included articles, which investigated cold-brew coffees

\begin{tabular}{|c|c|c|c|}
\hline Authors & Article type/ Population & Methods & Conclusions \\
\hline$\underline{\mathrm{Xu}}$ et al, $2012[65]$ & Research article & $\begin{array}{l}\text { Investigate the profiles of antioxidant and DNA-protective } \\
\text { activities of chlorogenic acid isomers }\end{array}$ & $\begin{array}{l}\text { Hot coffee contains more antioxidants than cold brew coffee, } \\
\text { there are some strong antioxidants in cold brew coffee, such as } \\
\text { caffeoylquinic acid (CQA). }\end{array}$ \\
\hline$\frac{\text { Tallis et al, 2013, }}{[50]}$ & $\begin{array}{l}\text { Research Article- Older adults } \\
\text { ( } 9 \text { females and } 3 \text { males) }\end{array}$ & $\begin{array}{l}\text { Caffeine ( } 3 \mathrm{mg} / \mathrm{kg} \text { body mass) or a placebo. mood state by } \\
\text { BRUMS and coincidence anticipation performance by Bassin }\end{array}$ & $\begin{array}{l}\text { Every cup of coffee per day reduced risk of depression by about } \\
8 \% \text {, boosts mood and brain function by } 17 \% \text {. }\end{array}$ \\
\hline$\underline{\text { Liang and Kitts, }}$ & Review article & Chlorogenic acids in oxidative and inflammatory stress conditions & $\begin{array}{l}\text { Mitigating oxidative stress. CGAs exhibit anti-inflammatory } \\
\text { activities by modulating a number of important metabolic } \\
\text { pathways. }\end{array}$ \\
\hline$\underline{\text { Fuller and Rao, }}$ & $\begin{array}{l}\text { Research article/ Coffee } \\
\text { samples }\end{array}$ & Cold and hot methods & $\begin{array}{l}\text { 3-CGA concentrations and } \mathrm{pH} \text { were comparable between cold } \\
\text { and hot brews. Caffeine concentrations in cold brew coarse grind } \\
\text { samples were higher than their hot brew counterparts. }\end{array}$ \\
\hline$\frac{\text { Wierzejska, }}{[60]} 2017$ & Review article & $\begin{array}{l}\text { Analysis of compounds in coffee (Phenolic, norharman and } \\
\text { Harman) }\end{array}$ & $\begin{array}{l}\text { Moderate consumption reduce the risk for common } \\
\text { neurodegenerative conditions, i.e. Alzheimer's and Parkinson's } \\
\text { diseases. }\end{array}$ \\
\hline$\underline{\text { Shin, }, 2017[62]}$ & Research article & $\begin{array}{l}\text { Chemical characteristics and immune-modulating activity of } \\
\text { polysaccharides isolated (CCP-0) from Cold-Brew Coffee }\end{array}$ & $\begin{array}{l}\text { CCP-0 potentially enhance macrophage functions and the } \\
\text { intestinal immune system. }\end{array}$ \\
\hline $\begin{array}{l}\text { Rao and Fuller, } \\
2018[32]\end{array}$ & $\begin{array}{l}\text { Research article/ } \\
\text { Brazil, Ethiopia, Columbia, } \\
\text { Myanmar, Mexico. }\end{array}$ & $\begin{array}{l}\text { Cold brew coffee chemistry was compared to that of hot brew } \\
\text { coffee }\end{array}$ & $\begin{array}{l}\text { PH values of the cold and hot brew samples were ranging from } \\
4.85 \text { to } 5.13 \text {. Concentration of titratable acids and antioxidant } \\
\text { activity correlated poorly with total CQA concentration in hot } \\
\text { brew coffee. }\end{array}$ \\
\hline $\begin{array}{l}\text { Artalejo and García, } \\
2018[51]\end{array}$ & Condensed review & Coffee Consumption & $\begin{array}{l}\text { Phenolic compounds, magnesium, trigonline, and quinoids } \\
\text { reduce the risk of heart disease by up to } 15 \% \text {, increase insulin } \\
\text { sensitivity, stabilize blood sugar, and lower blood pressure }\end{array}$ \\
\hline$\frac{\text { Ross }}{[57]}$ et al, 2018 & $\begin{array}{l}\text { Research article/ Three instant } \\
\text { coffee extracts and six coffee } \\
\text { components [caffeine, } \\
\text { chlorogenic acid, quinic acid, } \\
\text { caffeic acid, quercetin, and } \\
\text { phenylindane] }\end{array}$ & $\begin{array}{l}\text { Inhibition of A } \beta \text { and } \alpha \text {-synuclein oligomerization was assessed } \\
\text { using ELISA assays }\end{array}$ & $\begin{array}{l}\text { Inhibit fibrillization of } A \beta \text { and tau, and promote } \alpha \text {-synuclein } \\
\text { oligomerization. Coffee component } 6 \text {, is a potent inhibitor of } \\
\text { both } A \beta \text { and tau fibrillization, and also inhibits } A \beta \\
\text { oligomerization. }\end{array}$ \\
\hline$\underline{\text { Heo et al, } 2019[34]}$ & Research article & $\begin{array}{l}\text { Acceptability and perceived sensory attributes of cold brew coffee } \\
\text { by check-all-that-apply (CATA) method }\end{array}$ & $\begin{array}{l}\text { Consumers' liking were not influenced by caffeine contents and } \\
\text { volatile compounds, but chlorogenic acid and trigonelline } \\
\text { contents were negatively related with sensory data. }\end{array}$ \\
\hline
\end{tabular}




\begin{tabular}{|c|c|c|c|c|}
\hline Authors & Article type/ Population & Treatment & independent variable & Conclusions \\
\hline $\begin{array}{l}\text { Kendler et al, } \\
2008 \text { [73] }\end{array}$ & Research article/ 1796 male & $\begin{array}{l}\text { Genes and environment factors } \\
\text { from early adolescence through } \\
\text { middle adulthood }\end{array}$ & Level of use of caffeine recorded for every year & $\begin{array}{l}\text { Initiation and early patterns of use influenced by social and familial } \\
\text { environmental factors while later levels influenced by genetic } \\
\text { factors }\end{array}$ \\
\hline $\begin{array}{l}\text { Foskett et al, } \\
2009[69]\end{array}$ & Research article/ 12 male soccer & $\begin{array}{l}6 \mathrm{mg} / \mathrm{kg} \text { body mass of caffeine or } \\
\text { a placebo in a double-blind } \\
\text { fashion } 60 \mathrm{~min} \text { before exercise }\end{array}$ & $\begin{array}{l}\text { Two 90-min soccer-specific intermittent running } \\
\text { trials with tests of soccer skill (LSPT). }\end{array}$ & $\begin{array}{l}\text { Improve players' passing accuracy and jump performance without } \\
\text { any detrimental effects on other performance parameters. }\end{array}$ \\
\hline $\begin{array}{l}\text { Richards and } \\
\text { Smith, } 2016[44]\end{array}$ & Review article & Energy Drinks & Mental Health (Stress, Anxiety, and Depression) & $\begin{array}{l}\text { Positive associations between energy drink consumption and } \\
\text { symptoms of mental health problems. }\end{array}$ \\
\hline 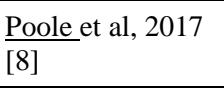 & Umbrella review & Coffee consumption & Multiple health outcomes & $\begin{array}{l}\text { Generally safe within usual levels of intake, largest risk reduction } \\
\text { for various health outcomes at three to four cups a day. }\end{array}$ \\
\hline$\frac{\text { Southward et al, }}{2018[14]}$ & Systematic review & Acute caffeine ingestion & Endurance Performance & $\begin{array}{l}\text { Small but evident effect in moderate doses }(3-6 \mathrm{mg} / \mathrm{kg}) \text { and } \\
\text { improvement in mean power output }\end{array}$ \\
\hline $\begin{array}{l}\text { Astley et al, } 2018 \\
\text { [81] }\end{array}$ & $\begin{array}{l}\text { Research article/ } 15 \text { resistance- } \\
\text { trained males }\end{array}$ & $\begin{array}{l}2.5 \mathrm{mg} / \mathrm{kg} \text { body weight of } \\
\text { caffeine or a placebo }\end{array}$ & $\begin{array}{l}80 \% 1 \mathrm{RM} \text { in the bench press exercise and } \\
\text { unilateral knee extension, maximal isometric } \\
\text { hand-grip test, standing long jump and repeated } \\
\text { sprint ability test }\end{array}$ & $\begin{array}{l}\text { Increase performance only in specific strength tests in resistance } \\
\text { trained men. }\end{array}$ \\
\hline 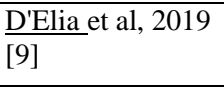 & Editorial & Caffeine and coffee & Human functioning & $\begin{array}{l}\text { The utility of coffee and caffeine to produce a change in human } \\
\text { functioning. }\end{array}$ \\
\hline$\frac{\text { Del Coso et al, }}{2019[10]}$ & Meta-analysis & Dose-response of coffee & Hypertension & $\begin{array}{l}\text { Moderate coffee intake is not associated with risk of HPT, non- } \\
\text { linear inverse dose-response relationship between coffee } \\
\text { consumption and risk of HPT. }\end{array}$ \\
\hline 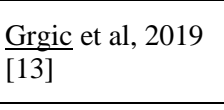 & Systematic review & Caffeine supplementation & Exercise performance & $\begin{array}{l}\text { Ergogenic effects on muscle endurance, muscle strength, anaerobic } \\
\text { power and aerobic endurance. The effect is greater for aerobic } \\
\text { exercise. }\end{array}$ \\
\hline 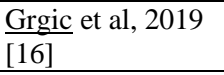 & Review article & Caffeine supplementation & Resistance exercise & $\begin{array}{l}\text { Coffee equally ergogenic as caffeine alone. Doses in the range of } \\
3-9 \mathrm{mg} / \mathrm{kg} \text { to be adequate when administered } 60 \mathrm{~min} \text { pre-exercise. }\end{array}$ \\
\hline 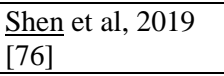 & $\begin{array}{l}\text { Systematic review and meta- } \\
\text { analysis }\end{array}$ & Caffeine and placebo groups & Duration of endurance athletic time trial events & $\begin{array}{l}\text { Effect size of caffeine increases along with the increasing duration } \\
\text { of the time trial event. }\end{array}$ \\
\hline$\frac{\text { Salinero et a, }}{2019[79]}$ & $\begin{array}{l}\text { Systematic review and meta- } \\
\text { analysis }\end{array}$ & Acute ingestion of caffeine & Team sports performance & $\begin{array}{l}\text { Increase single and repeated jump height, sprint velocity and } \\
\text { reduced the time to complete agility tests. During team sport } \\
\text { matches increase running distance, distance covered at sprint } \\
\text { velocity and number. }\end{array}$ \\
\hline $\begin{array}{l}\text { Mielgo et al, } \\
2019[83]\end{array}$ & $\begin{array}{l}\text { Systematic review/men and } \\
\text { women }\end{array}$ & Caffeine supplementation & Sports performance & $\begin{array}{l}\text { Similar benefit for aerobic performance and the fatigue index in } \\
\text { men and women athletes. Produce more power, total weight lifted } \\
\text { and to improve sprint performance was higher in men than women } \\
\text { athletes. }\end{array}$ \\
\hline 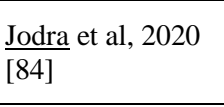 & $\begin{array}{l}\text { Research article/ } 8 \text { elite athletes } \\
\text { and } 10 \text { trained-recreational } \\
\text { athletes }\end{array}$ & $\begin{array}{l}\text { Caffeine supplementation } \\
(6 \mathrm{mg} / \mathrm{kg}) \text { or placebo }\end{array}$ & $\begin{array}{l}\text { Wingate test and questionnaires Profiles of } \\
\text { Moods States (POMS) }\end{array}$ & $\begin{array}{l}\text { Improve anaerobic performance in both the elite and recreational } \\
\text { athletes. The ergogenic effect on several mood dimensions and } \\
\text { subjective vitality was greater in the elite athletes. }\end{array}$ \\
\hline
\end{tabular}


Normally, caffeine improves endurance performance, adaptation to endurance training and improves health by accelerating the metabolic activities caused by muscle contractions $(78,79)$. In team exercises, moderate doses of caffeine include positive effects on several aspects of physical functions, including increased single and repeated jump heights, number of steps, running speeds, and decreased agility test times (80). Consumption of caffeinated beverages $60 \mathrm{~min}$ before the exercise improves physical performance in strength and exercise specific efforts $(16,81)$. Assessing effects of caffeine intake on various physical functions of men, only results of specific strength tests such as superior knee extension, bench press and isometric hand strength are affected (82). Analysis of existing studies shows that caffeine intake increases anaerobic power and aerobic endurance (83). However, effects of caffeine in aerobic exercises seem greater than those in anaerobic exercises (13). Furthermore, caffeine consumption includes similar ergogenic benefits in aerobic functions and fatigue indices in men and women. However, these effects are further significant in men in anaerobic functions (84). Recent studies on effects of caffeine on physical performances and mood dimensions of expert and trained athletes show that caffeine improves anaerobic performances of athletes in both groups, while mood and vitality of expert athletes are more affected by the ergogenic effects of caffeine $(17,85)$.

\section{Conclusion}

In conclusion, results of this review study have shown that daily consumption of three to four cups of coffee with moderate doses of caffeine (300-400 $\mathrm{mg}$ ) includes positive effects on human well-being and can partially prevent mental and physical disorders. However, benefits of cold-brew coffee seem greater because of its low acidity and high antioxidant activity with no digestive problems. Therefore, further studies are necessary to investigate and compare acute and chronic effects of consumption of various coffee beans. Results have shown that caffeine intake improves physical performance in trainings and exercises such as strength protocols, jumps, endurance tests and specific exercise movements. However, further studies are needed to group specific physical and sport performances to assess health effects of coffees, including cold-brew coffees.

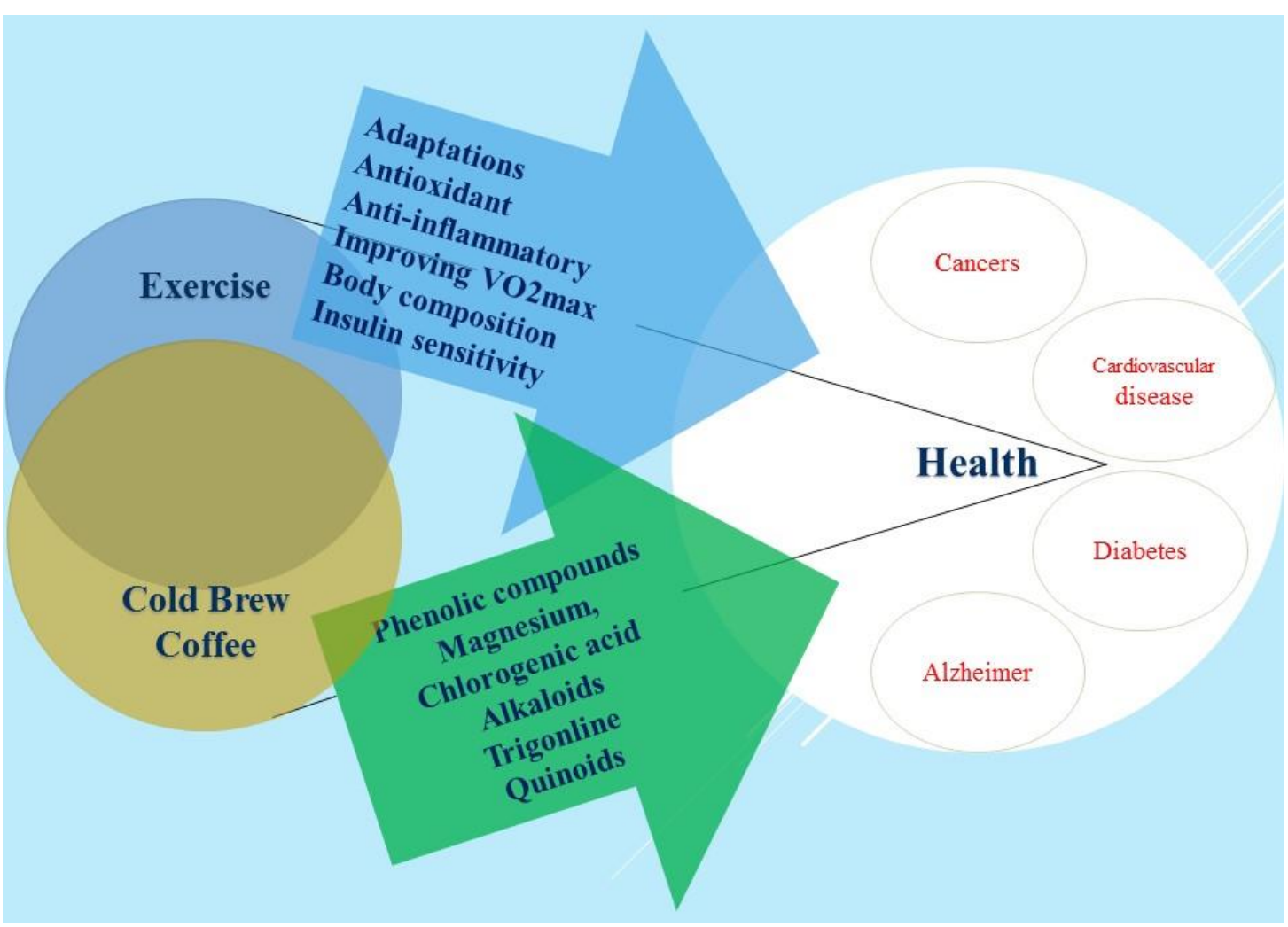

Figure 2. Useful effects of exercise and cold-brew coffee on health 


\section{Acknowledgement}

The authors express their gratitude to Amir Hasan Torkaman Far and Eve Wellness Lounge (Eve Wellness Club) for scientific advices on methods of coffee production and its effects on health and wellness. The authors declare no conflict of interest and no funding for this study.

\section{Financial disclosure}

The authors declared no financial interest.

\section{References}

1. Karimnezhad n, Mahdavi Roshan M, Izaddoust F, Shabani R. The Simultaneous Effects of Green Coffee and Combine Exercise Training on Body Composition and Glucose Homeostasis in Obese and Overweight Women. JOURNAL OF MEDICINAL PLANTS. 2019;18(72 \#b00671):215-27.

2. de Lima LM, de Pellegrini Elias L, e Silva MMCD, da Silva KV, Pacheco ASV. Chapter 16 - Behavioral aspects of the coffee consumer in different countries: The case of Brazil. In: de Almeida LF, Spers EE, editors. Coffee Consumption and Industry Strategies in Brazil: Woodhead Publishing; 2020. p. 321-41.

3. Reyes CM, Cornelis MC. Caffeine in the Diet: CountryLevel Consumption and Guidelines. Nutrients. 2018;10(11).

4. Salari-Moghaddam A, Milajerdi A, Surkan PJ, Larijani B, Esmaillzadeh A. Caffeine, Type of Coffee, and Risk of Ovarian Cancer: A Dose-Response Meta-Analysis of Prospective Studies. J Clin Endocrinol Metab. 2019;104(11):5349-59.

5. Cano-Marquina A, Tarin JJ, Cano A. The impact of coffee on health. Maturitas. 2013;75(1):7-21.

6. Nuhu AA. Bioactive micronutrients in coffee: recent analytical approaches for characterization and quantification. ISRN Nutr. 2014;2014:384230-.

7. Ahmadifar M, Nateghi R. The effect of caffeine intake on the risk of cardiovascular disease. Scientific Journal Management System. 2015;5(19):58-71.

8. Poole R, Kennedy OJ, Roderick P, Fallowfield JA, Hayes PC, Parkes J. Coffee consumption and health: umbrella review of meta-analyses of multiple health outcomes. Bmj. 2017;359:j5024.

9. Del Coso J, Salinero JJ, Lara B. Effects of Caffeine and Coffee on Human Functioning. Nutrients. 2020;12(1).

10. D'Elia L, Fata E, Galletti F, Scalfi L, Strazzullo P. Coffee consumption and risk of hypertension: a doseresponse meta-analysis of prospective studies. European Journal of Nutrition. 2017;58.

11. Mousavi A, Koushki Jahromi M, Salesi M, Daryanoush F, Khoshnam E, Nikseresht A, et al. Impact of caffeine consumption on heart rate and blood pressure during rest and exercise. jumsjmj. 2011;9(1):7-13.
12. Del Coso J, Muñoz G, Muñoz-Guerra J. Prevalence of caffeine use in elite athletes following its removal from the World Anti-Doping Agency list of banned substances. Applied Physiology, Nutrition, and Metabolism. 2011;36(4):555-61.

13. Grgic J, Grgic I, Pickering C, Schoenfeld B, Bishop D, Pedisic Z. Wake up and smell the coffee: caffeine supplementation and exercise performance-An umbrella review of 21 published meta-analyses. British Journal of Sports Medicine. 2019.

14. Southward K, Rutherfurd-Markwick K, Ali A. The Effect of Acute Caffeine Ingestion on Endurance Performance: A Systematic Review and Meta-Analysis. Sports Medicine. 2018;48.

15. Taheri M, Irandoost K, Yousefi S, Jamali A. Effect of 8Week Lower Extremity Weight-Bearing Exercise Protocol and Acute Caffeine Consumption on Reaction Time in Postmenopausal Women. Yektaweb_Journals. 2017;12(1):18-29.

16. Grgic J, Mikulic P, Schoenfeld B, Bishop D, Pedisic Z. The Influence of Caffeine Supplementation on Resistance Exercise: A Review. Sports Medicine. 2018;49.

17. Pickering C, Grgic J. Caffeine and Exercise: What Next? Sports Med. 2019;49(7):1007-30.

18. Burke LM. Practical Issues in Evidence-Based Use of Performance Supplements: Supplement Interactions, Repeated Use and Individual Responses. Sports Med. 2017;47(Suppl 1):79-100.

19. Adhikari J, Chambers Et, Koppel K. Impact of consumption temperature on sensory properties of hot brewed coffee. Food Res Int. 2019;115:95-104.

20. Sanchez Alan K, Chambers E. How Does Product Preparation Affect Sensory Properties? An Example with Coffee. Journal of Sensory Studies. 2015;30:n/an/a.

21. Farah A, Monteiro MC, Calado V, Franca AS, Trugo LC. Correlation between cup quality and chemical attributes of Brazilian coffee. Food Chemistry. 2006;98(2):373-80.

22. Esquivel P, Jiménez VM. Functional properties of coffee and coffee by-products. Food Research International. 2012;46(2):488-95.

23. Kanjanakorn A, Lee J. Examining emotions and comparing the EsSense Profile ${ }^{\circledR}$ and the Coffee Drinking Experience in coffee drinkers in the natural environment. Food Quality and Preference. 2017;56:6979.

24. Angeloni G, Guerrini L, Masella P, Innocenti M, Bellumori M, Parenti A. Characterization and comparison of Cold Brew and Cold Drip Coffee Extraction Methods. Journal of the Science of Food and Agriculture. 2018.

25. Naveed M, Hejazi V, Abbas M, Kamboh AA, Khan GJ, Shumzaid M, et al. Chlorogenic acid (CGA): A 
pharmacological review and call for further research. Biomedicine \& Pharmacotherapy. 2018;97:67-74.

26. Akiyama M, Murakami K, Hirano Y, Ikeda M, Iwatsuki K, Wada A, et al. Characterization of Headspace Aroma Compounds of Freshly Brewed Arabica Coffees and Studies on a Characteristic Aroma Compound of Ethiopian Coffee. Journal of food science. 2008;73:C335-46.

27. Blumberg S, Frank O, Hofmann T. Quantitative Studies on the Influence of the Bean Roasting Parameters and Hot Water Percolation on the Concentrations of Bitter Compounds in Coffee Brew. Journal of agricultural and food chemistry. 2010;58:3720-8.

28. Sato Y, Itagaki S, Kurokawa T, Ogura J, Kobayashi M, Hirano $\mathrm{T}$, et al. In vitro and in viva antioxidant properties of chlorogenic acid and cafeic acid. International journal of pharmaceutics. 2010;403:136-8.

29. Fuller M, Rao NZ. The Effect of Time, Roasting Temperature, and Grind Size on Caffeine and Chlorogenic Acid Concentrations in Cold Brew Coffee. Sci Rep. 2017;7(1):17979-.

30. Rao NZ, Fuller M. Acidity and Antioxidant Activity of Cold Brew Coffee. Sci Rep. 2018;8(1):16030-.

31. Kubo A, Block G, Quesenberry CP, Jr., Buffler P, Corley DA. Dietary guideline adherence for gastroesophageal reflux disease. BMC Gastroenterol. 2014;14:144-.

32. Piccioni A, Covino M, Zanza C, Longhitano Y, Tullo G, Bonadia N, et al. Energy Drinks: A Narrative Review Of Their Physiological And Pathological Effects. Internal Medicine Journal. 2020;10.1111/imj.14881(accepted for publication).

33. Grosso G, Micek A, Godoś J, Sciacca S, Pajak A, Martínez-González M, et al. Coffee consumption and risk of all-cause, cardiovascular, and cancer mortality in smokers and non-smokers: a dose-response metaanalysis. European Journal of Epidemiology. 2016;31.

34. Samoggia A, Riedel B. Consumers' Perceptions of Coffee Health Benefits and Motives for Coffee Consumption and Purchasing. Nutrients. 2019;11(3).

35. Heo J, Choi KS, Wang S, Adhikari K, Lee J. Cold Brew Coffee: Consumer Acceptability and Characterization Using the Check-All-That-Apply (CATA) Method. Foods. 2019;8(8):344.

36. Mahoney CR, Giles GE, Marriott BP, Judelson DA, Glickman EL, Geiselman PJ, et al. Intake of caffeine from all sources and reasons for use by college students. Clinical Nutrition. 2019;38(2):668-75.

37. Cornelis MC, Munafo MR. Mendelian Randomization Studies of Coffee and Caffeine Consumption. Nutrients. 2018;10(10):1343.

38. B Barnung R, H Nøst T, Ulven SM, Skeie G, S Olsen K. Coffee Consumption and Whole-Blood Gene Expression in the Norwegian Women and Cancer Post-Genome Cohort. Nutrients. 2018;10(8):1047.
39. van Dijk R, Ties D, Kuijpers D, van der Harst P, Oudkerk M. Effects of Caffeine on Myocardial Blood Flow: A Systematic Review. Nutrients. 2018;10(8):1083.

40. Yaya I, Marcellin F, Costa M, Morlat P, Protopopescu C, Pialoux G, et al. Impact of Alcohol and Coffee Intake on the Risk of Advanced Liver Fibrosis: A Longitudinal Analysis in HIV-HCV Coinfected Patients (ANRS HEPAVIH CO-13 Cohort). Nutrients. 2018;10(6):705.

41. Navarro AM, Abasheva D, Martínez-González MÁ, Ruiz-Estigarribia L, Martín-Calvo N, Sánchez-Villegas A, et al. Coffee Consumption and the Risk of Depression in a Middle-Aged Cohort: The SUN Project. Nutrients. 2018;10(9):1333.

42. Lee S-Y, Jung G, Jang M-J, Suh M-W, Lee JH, Oh SH, et al. Association of Coffee Consumption with Hearing and Tinnitus Based on a National Population-Based Survey. Nutrients. 2018;10(10):1429.

43. Haller S, Montandon M-L, Rodriguez C, Herrmann FR, Giannakopoulos P. Impact of Coffee, Wine, and Chocolate Consumption on Cognitive Outcome and MRI Parameters in Old Age. Nutrients. 2018;10(10):1391.

44. Gkegkes ID, Minis EE, Iavazzo C. Effect of Caffeine Intake on Postoperative Ileus: A Systematic Review and Meta-Analysis. Digestive Surgery. 2020;37(1):22-31.

45. Richards G, Smith AP. A Review of Energy Drinks and Mental Health, with a Focus on Stress, Anxiety, and Depression. Journal of Caffeine Research. 2016;6(2):4963.

46. KÜÇEr N. The relationship between daily caffeine consumption and withdrawal symptoms: A questionnaire-based study. Turkish Journal of Medical Sciences. 2010;40.

47. Verster J. Caffeine Consumption in Children, Adolescents and Adults. Current drug abuse reviews. 2015;7.

48. Wolfson A. Adolescents and Emerging Adults' Sleep Patterns: New Developments. The Journal of adolescent health : official publication of the Society for Adolescent Medicine. 2010;46:97-9.

49. Acheson K, Gremaud G, Meirim I, Montigon F, Krebs Y, Fay L, et al. Metabolic effects of caffeine in humans: Lipid oxidation or futile cycling? The American journal of clinical nutrition. 2004;79:40-6.

50. Wang L, Shen X, Wu Y, Zhang D. Coffee and caffeine consumption and depression: A meta-analysis of observational studies. The Australian and New Zealand journal of psychiatry. 2015;50.

51. Tallis J, Duncan MJ, Wright SL, Eyre ELJ, Bryant E, Langdon D, et al. Assessment of the ergogenic effect of caffeine supplementation on mood, anticipation timing, and muscular strength in older adults. Physiol Rep. 2013;1(3):e00072-e. 
52. Artalejo F, Garcia E. Coffee Consumption and Cardiovascular Disease: A Condensed Review of Epidemiological Evidence and Mechanisms. Journal of Agricultural and Food Chemistry. 2017;66.

53. Liang N, Kitts DD. Role of Chlorogenic Acids in Controlling Oxidative and Inflammatory Stress Conditions. Nutrients. 2015;8(1):16.

54. Turnbull D, Rodricks JV, Mariano GF, Chowdhury F. Caffeine and cardiovascular health. Regulatory Toxicology and Pharmacology. 2017;89:165-85.

55. Carlsson S, Hammar N, Grill V, Kaprio J. Coffee consumption and risk of type 2 diabetes in Finnish twins. International journal of epidemiology. 2004;33:616-7.

56. Muley A, Muley P, Shah M. Coffee to Reduce Risk of Type 2 Diabetes? : A Systematic Review. Current diabetes reviews. 2012;8:162-8.

57. Moeenfard M, Rocha L, Alves A. Quantification of Caffeoylquinic Acids in Coffee Brews by HPLC-DAD. J Anal Methods Chem. 2014;2014:965353-.

58. Mancini RS, Wang Y, Weaver DF. Phenylindanes in Brewed Coffee Inhibit Amyloid-Beta and Tau Aggregation. Front Neurosci. 2018;12:735-.

59. Eskelinen M, Kivipelto M. Caffeine as a Protective Factor in Dementia and Alzheimer's Disease. Journal of Alzheimer's disease : JAD. 2010;20 Suppl 1:S167-74.

60. Hernán M, Takkouche B, Caamano-Isorna F, Gestal Otero JJ. A Meta-analysis of Coffee Drinking, Cigarette Smoking, and the Risk of Parkinson's Disease. Annals of neurology. 2002;52:276-84.

61. Wierzejska R. Can coffee consumption lower the risk of Alzheimer's disease and Parkinson's disease? A literature review. Archives of Medical Science. 2016;13.

62. Xu L, Lao F, Xu Z, Wang X, Chen F, Liao X, et al. Use of Liquid Chromatography Quadrupole Time-of-Flight Mass Spectrometry and Metabolomic Approach to Discriminate Coffee Brewed by Different Methods. Food Chemistry. 2019;286.

63. Shin K-S. The Chemical Characteristics and ImmuneModulating Activity of Polysaccharides Isolated from Cold-Brew Coffee. Preventive Nutrition and Food Science. 2017;22:100-6.

64. Nordestgaard A, Nordestgaard B. Coffee intake, cardiovascular disease and all-cause mortality: observational and Mendelian randomization analyses in 95 000-223 000 individuals. International journal of epidemiology. 2016;45.

65. Teixeira J, Gaspar A, Garrido EM, Garrido J, Borges F. Hydroxycinnamic acid antioxidants: an electrochemical overview. Biomed Res Int. 2013;2013:251754-.

66. Xu J-G, Hu Q-P, Liu Y. Antioxidant and DNAProtective Activities of Chlorogenic Acid Isomers. Journal of agricultural and food chemistry. 2012;60.
67. Jafari A, Farajpour Khazaei S, Alipour M. Effect of onemonth concurrent training with or without caffeine supplementation on resting energy expenditure and leptin resistance in overweight women. DANESHVAR MEDICINE. 2019;27(140 \#T00271):37-46.

68. Hurst P, Schipof-Godart L, Szabo A, Raglin J, Hettinga F, Roelands B, et al. The Placebo and Nocebo effect on sports performance: A systematic review. European Journal of Sport Science. 2019:1-14.

69. Saunders B, Oliveira L, Silva R, Painelli V, Gonçalves L, Yamaguchi G, et al. Placebo in sports nutrition: A proof-of-principle study involving caffeine supplementation. Scandinavian Journal of Medicine \& Science in Sports. 2016;27.

70. Foskett A, Ali A, Gant N. Caffeine Enhances Cognitive Function and Skill Performance During Simulated Soccer Activity. International journal of sport nutrition and exercise metabolism. 2009;19:410-23.

71. Pickering C, Kiely J. Are the Current Guidelines on Caffeine Use in Sport Optimal for Everyone? Interindividual Variation in Caffeine Ergogenicity, and a Move Towards Personalised Sports Nutrition. Sports Medicine. 2017;48.

72. Bchir F, Dogui M, Ben Fradj R, Arnaud MJ, Saguem S. Differences in pharmacokinetic and electroencephalographic responses to caffeine in sleepsensitive and non-sensitive subjects. Comptes Rendus Biologies. 2006;329(7):512-9.

73. Abraham J, Mudd J, Kapur N, Klein K, Champion H, Wittstein I. Stress Cardiomyopathy After Intravenous Administration of Catecholamines and Beta-Receptor Agonists. Journal of the American College of Cardiology. 2009;53:1320-5.

74. Kendler K, Schmitt J, Aggen S, Prescott C. Genetic and Environmental Influences on Alcohol, Caffeine, Cannabis, and Nicotine Use From Early Adolescence to Middle Adulthood. Archives of general psychiatry. 2008;65:674-82.

75. Southward K, Rutherfurd-Markwick K, Badenhorst C, Ali A. The Role of Genetics in Moderating the InterIndividual Differences in the Ergogenicity of Caffeine. Nutrients. 2018;10(10):1352.

76. Shabir A, Hooton A, Tallis J, Higgins M. The Influence of Caffeine Expectancies on Sport, Exercise, and Cognitive Performance. Nutrients. 2018;10:1528.

77. Shen J, Brooks M, Cincotta J, Manjourides J. Establishing a relationship between the effect of caffeine and duration of endurance athletic time trial events: A systematic review and meta-analysis. Journal of Science and Medicine in Sport. 2018;22.

78. Rosser J, Walsh B, Hogan M. Effect of physiological levels of caffeine on $\mathrm{Ca} 2+$ handling and fatigue development in Xenopus isolated single myofibers. American journal of physiology Regulatory, integrative and comparative physiology. 2009;296:R1512-7. 
79. Rothschild J, Bishop D. Effects of Dietary Supplements on Adaptations to Endurance Training. Sports Medicine. $2019 ; 50$

80. Salinero J, Lara B, Del Coso J. Effects of acute ingestion of caffeine on team sports performance: a systematic review and meta-analysis. Research in Sports Medicine. 2018;27:1-19.

81. Souza D, Del Coso J, Casonatto J, Polito M. Acute effects of caffeine-containing energy drinks on physical performance: a systematic review and meta-analysis. European Journal of Nutrition. 2016;56.

82. Astley C, Souza D, Polito M. Acute Specific Effects of Caffeine-containing Energy Drink on Different Physical Performances in Resistance-trained Men. International Journal of Exercise Science. 2018;11:260-8.

83. Forati H, Hojjati Z, Rahmani Nia F. The Effect of Caffein Consumption on Muscular Strenght and
Endurance in Amateur Male Soccer Players Journal of Practical Studies at Biosciences in Sport 2015;2(4):6877.

84. Mielgo-Ayuso J, Marqués-Jiménez D, Román I, Del Coso J, León-Guereño P, Calleja Gonzalez J. Effect of Caffeine Supplementation on Sports Performance Based on Differences Between Sexes: A Systematic Review. Nutrients. 2019;11:2313.

85. Jodra P, Lago A, Sanchez-Oliver A, Lopez-Samanes A, Pérez-López A, Herreros P, et al. Effects of caffeine supplementation on physical performance and mood dimensions in elite and trained-recreational athletes. Journal of the International Society of Sports Nutrition. 2020; 17 . 